\title{
A (des)democratização do Brasil e a negação da educação como um direito
}

\author{
CATARINA DE ALMEIDA SANTOS* \\ Universidade de Brasília, Brasília- DF, Brasil
}

LEDA SCHEIBE**

Universidade do Oeste de Santa Catarina, Joaçaba- SC, Brasil

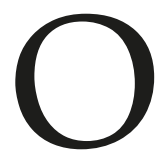

objetivo do Dossiê “(Des)democratização da Educação Brasileira” é dialogar com os leitores sobre os rumos da educação no País, no momento em que os direitos sociais fundamentais estão em risco. Após uma breve análise do contexto mais amplo e do cenário em que surgem e no qual estão sendo implementados, serão apresentadas as políticas, os projetos e as ações analisadas pelos diversos autores que enviaram textos.

No dia 05 de outubro de 1988, o Congresso Nacional, reunido em Assembleia Nacional Constituinte, ao promulgar a Constituição da República Federativa do Brasil (CF) institui, após 21 anos de ditadura civil militar (1964-1985), o Estado Democrático de Direito. No Preâmbulo da Constituição, o Congresso declara que o Estado, então instituído, se destina a assegurar aos cidadãos brasileiros e aos estrangeiros residentes no País "o exercício dos direitos sociais e individuais, a liberdade, a segurança, o bem-estar, o desenvolvimento, a igualdade e a justiça como valores supremos de uma sociedade fraterna, pluralista e sem preconceitos, fundada na harmonia social e comprometida, na ordem interna e internacional, com a solução pacífica das controvérsias"' (BRASIL, 1988).

De Acordo com o Art. $3^{\circ}$ do texto constitucional, a República Federativa do Brasil tem, entre seus objetivos fundamentais, a construção de uma sociedade livre, justa e solidária; a garantia do desenvolvimento nacional; a erradicação da pobreza, da marginalização e a redução das desigualdades sociais e regionais, além da promoção do bem de todos, sem preconceitos de origem, raça, sexo, cor, idade e quaisquer outras formas de discriminação (BRASIL, 1988).

* Doutora em Educação pela Universidade de São Paulo e mestra também em Educação pela Universidade Federal de Goiás. Atualmente é professora adjunta da Faculdade de Educação da Universidade de Brasília. Compõe o Comitê Editorial da Revista Retratos da Escola. E-mail:<cdealmeidasantos@gmail.com>.

** É professora do Programa de Pós-graduação em Educação da Universidade do Oeste de Santa Catarina e editora chefe da Retratos da Escola. E-mail: <lscheibe@uol.com.br>. 
Os direitos sociais fundamentais a que o Preâmbulo do texto constitucional alude dizem respeito à educação, saúde, alimentação, trabalho, moradia, transporte, lazer, segurança, previdência social, proteção à maternidade e à infância, assistência aos desamparados, e devem ser atendidos na forma desta Constituição (BRASIL, 1988, Art. $6^{\circ}$ ). Para a garantia desses direitos a Constituição, nos artigos subsequentes, delega ao Estado Brasileiro um conjunto de deveres e responsabilidades, assim como cria uma série de estruturas para viabilizar a implementação de cada um deles.

A Carta Magna de 1988 passou a ser denominada de Constituição Cidadã, tendo em vista a abrangência dos direitos por ela instituídos em benefício dos direitos humanos e da cidadania. Podemos tomar como exemplo os direitos à educação e saúde. O Art. 205 define que a educação é direito de todos e dever do Estado e da família, devendo contar com a colaboração da sociedade para sua promoção e incentivo. Ao estabelecer a educação como direito, a Constituição define os objetivos fundamentais que se precisa alcançar: o pleno desenvolvimento da pessoa para exercer a sua cidadania e conviver em sociedade, qualificando-a para o mundo do trabalho.

A saúde como direito social é definida no Art. 196 como " direito de todos e dever do Estado, garantido mediante políticas sociais e econômicas que visem à redução do risco de doença e de outros agravos e ao acesso universal e igualitário às ações e serviços para sua promoção, proteção e recuperação" (BRASIL, 1988). Para a consecução deste direito, a Constituição criou o maior sistema de saúde pública existente no mundo, cujas ações e serviços públicos, definidos no Art. 198, integram uma rede regionalizada e hierarquizada, constituída em um sistema único, organizado de forma descentralizada, com direção única em cada esfera de governo. Prevê também atendimento integral, com prioridade para as atividades preventivas, sem prejuízo dos serviços assistenciais; e contando com a participação da comunidade (BRASIL, 1988).

Os dois direitos sociais, educação e saúde, colocam o Brasil em uma posição peculiar, tendo em vista ser um dos poucos países do mundo ${ }^{1}$ a ter um sistema público de saúde universal, e único no mundo que atende a mais de 100 milhões de habitantes. Além disso, o Sistema Único de Saúde (SUS) brasileiro é um dos mais complexos, tendo em vista que possui desde o simples atendimento para avaliação da pressão arterial, por meio da atenção básica, até o transplante de órgãos, garantindo acesso integral, universal e gratuito para toda a população. ${ }^{2}$

Esta discussão é para compreender o que está em risco com as medidas adotadas nos últimos anos, após a aprovação do impeachment da presidenta Dilma Rousseff pelo Congresso Brasileiro: ao assumir a Presidência, Michel Temer colocou em prática as chamadas políticas de austeridade, sob a alegação de que tais medidas seriam capazes de reequilibrar a economia, reduzir a dívida pública e garantir o crescimento econômico. Segundo Dweck, Oliveira e Rossi: 


\begin{abstract}
"Austeridade" não é um termo de origem econômica, a palavra tem origens na filosofa moral e aparece no vocabulário econômico como um neologismo que se apropria da carga moral do termo, especialmente para exaltar o comportamento associado ao rigor, à disciplina, aos sacrifícios, à parcimônia, à prudência, à sobriedade e reprimir comportamentos dispendiosos, insaciáveis, pródigos, perdulários. O discurso moderno da austeridade ainda carrega essa carga moral e transpõe, sem adequadas mediações, essas supostas virtudes do indivíduo para o plano público, personificando, atribuindo características humanas ao governo (2018, p.17).
\end{abstract}

A defesa da implementação de medidas austeras com base em argumentos econômicos supostamente técnicos tem, sistematicamente, colocado em questão o pacto social da redemocratização brasileira, consolidado na Constituição de 1988. É esse pacto social que os ultraliberais vêm combatendo sob a alegação de que "o Estado brasileiro não cabe no PIB" ou que "as demandas sociais da democracia não cabem no orçamento", ou seja, que os direitos sociais aprovados na Constituição Federal de 1988 não cabem no orçamento brasileiro. Uma das medidas adotadas foi a aprovação da EC 95, que instituiu o Novo Regime Fiscal, no âmbito dos Orçamentos Fiscal e da Seguridade Social da União, para vigorar por vinte exercícios financeiros. Em outras palavras, congela por 20 anos os investimentos nas despesas primárias, ou seja, impede que haja novos investimentos nos direitos sociais por duas décadas.

As políticas de austeridade tão defendidas pelos ultraliberais vêm nos dizer que para o neoliberalismo é insuportável a ideia de um país possuir um sistema único de saúde universal, universidades públicas e gratuitas, pois, como aponta Tzvetan Todorov, as medidas defendidas pelos ultraliberais não se devem à aspiração de viver melhor, mas sim à "lógica do neoliberalismo que vê a humanidade como uma massa indiferenciada de indivíduos, eles próprios reduzidos apenas aos seus interesses econômicos" (2017, p. 126). O autor salienta que esse "esquecimento da dimensão social, constitutiva de cada ser humano, não é apenas um erro intelectual. Existe um perigo de, com base nesta imagem mutilada daquilo que funda a nossa humanidade, seguirmos uma política cujos efeitos seriam igualmente mutilantes" (p. 127).

Todorov nos lembra que há na tradição ocidental dois tipos de laços sociais que produzem relação de obrigação, e três instâncias. Os laços sociais são a lei e o contrato e as três instâncias são um eu e um tu, dois parceiros que entram em relação, além de um eles, o terceiro impessoal, que garantiria a validade dos compromissos assumidos. Mas esse terceiro, segundo ele, não assume sempre o mesmo papel na lei e no contrato, tendo em vista que, como aponta, se utilizando de A. Supiot, a lei são "os textos e as palavras que se nos impõem independente da nossa vontade" ao passo que o contrato refere-se "aos que procedem de um acordo livre com outrem". (p. 127).

No caso da lei, o terceiro fixa o próprio conteúdo da obrigação: aquilo que é interdito, permitido ou imposto, ao mesmo tempo que a necessidade de sujeição à lei. No caso do contrato, as partes contratantes decidem livremente o conteúdo, enquanto o 
terceiro se limita a caucionar a validade dos contratos: se não temos voz, caímos na alçada da lei. Esta traduz a vontade do povo, enquanto o contrato assenta na liberdade individual (ibdem).

A reflexão é importante para compreender que políticas de austeridade representam um recuo da lei em favor dos contratos, ou seja, passa pela lógica da retirada do Estado de garantidor dos direitos sociais. O Estado, quando muito, se torna mediador da relação que se dá entre contratantes e contratados por meio da criação de normas fluidas e flexíveis.

É nesse contexto que Governo e Congresso vêm buscando a todo custo ignorar ou descumprir o que está posto na Constituição de 1988, inclusive desconstitucionalizando-a por meio de emendas, que, em última instância, ferem a própria Constituição, como é o caso da EC 95/2016. A clareza sobre o que rege a lei e o contrato e o recuo da lei em favor da proliferação da lógica dos contratos, assim como seus desdobramentos, são, segundo Todorov importantes, tendo em vista que

\begin{abstract}
Essa distinção consagra o facto de certas normas e valores não relevarem da negociação entre indivíduos, pois foram decididas anteriormente, até antes de nascerem, independente da sua vontade. O que, por sua vez, nos lembra que a sociedade não se reduz à soma dos indivíduos que dela fazem parte, ao contrário do que dava a entender a expressão muitas vezes citada da antiga primeira-ministra britânica, a ultraliberal Margareth Thatcher: "A sociedade não existe". Por isso, dispomos, não só de direitos decorrentes da nossa pertença ao gênero humano - aquilo a que chamamos de direitos humanos -, mas também (e sobretudo) de direitos e deveres decorrentes da nossa pertença a uma sociedade particular (2017, p. 127-128).
\end{abstract}

O autor aponta que boa parte das sociedades humanas conseguiu avançar da lógica pré-moderna de que o papel de garantidor de qualquer obrigação era desempenhado pelas tradições ou pelos deuses, passando a ser confiado ao povo, o que na prática significou delegá-lo ao Estado, que exerce aí o papel do terceiro. $\mathrm{O}$ desaparecimento do terceiro garantidor, o que na prática seria a retirada do Estado, diz o autor, nos levaria a voltar ao reino animal, ou aquilo que "chamamos impropriamente da 'lei' da selva, estado no qual só a força conta", nos aproximando assim do regime totalitário, no qual o chefe do Estado não se sente submetido às leis, mas a sua própria vontade. Assim, ressalta ele que "se definirmos a barbárie como recusa de considerar que os outros são seres humanos semelhantes a nós, podemos ver nesse mundo regido apenas pelo poder uma encarnação bastante perfeita da barbárie" (p. 128).

É importante observar o que aponta o autor ao dizer que está em curso, já há algum tempo, nas democracias ocidentais, uma mutação nas relações em sociedade que consiste no aumento do domínio dos contratos e diminuição das leis, o que significa restringir o poder do povo e dar liberdade à vontade dos indivíduos. No mundo do trabalho isso se manifesta, segundo o autor, quando os patrões se queixam muito das leis ou 
regulamentações que lhes entravam a liberdade de ação, pois preferem negociar diretamente um contrato com os empregados. Todorov ressalta que

\begin{abstract}
Esta mutação recebeu uma forte aceleração com a globalização da economia. Idealmente, esta não depende de qualquer Estado ou qualquer legislação e, portanto, utiliza exclusivamente os contratos. Pouco lhe importam os países, lida apenas, sempre e apenas, com indivíduos, todos iguais, todos movidos pelos mesmos interesses materiais. A desproporção entre o poder de um dos parceiros em relação ao outro, porém, é gritante: a poderosa multinacional e o desempregado à procura de trabalho não entram realmente na mesma categoria. No lugar de Deus garantidor, já não está o Estado, mas o mercado, ou seja, o próprio meio de troca, que se torna o seu próprio fundamento (p. 130).
\end{abstract}

O Dossiê aqui apresentado traz um panorama analítico dos processos e projetos em curso no Brasil que demarcam o declinar da sua democracia por meio da implementação de diferentes projetos. No primeiro texto, Do FNE para o FNPE: a Conape como resistência, escrito por Luiz Dourado e Walisson Araújo, os autores expõem e problematizam o movimento recente de construção das Conferências Nacionais de Educação, além dos processos de inserção da sociedade civil no debate. Mostram, ainda, como as medidas encaminhadas pelo Governo Temer nos espaços de democracia participativa, os desmontes e as intervenções no Fórum Nacional de Educação levaram à constituição do Fórum Nacional Popular de Educação (FNPE) e à realização da Conferência Nacional Popular de Educação (Conape), com seu Plano de Lutas.

No segundo texto, Pior a Emenda que o soneto: os reflexos da EC 95/2016, Paulo de Sena Martins debate a política de austeridade fiscal imposta pelo Governo Federal, por meio da aprovação da Emenda Constitucional no 95 de 2016, e seus impactos nas políticas sociais, dentre estas, a educação, tendo em vista que o Novo Regime Fiscal, segundo o autor, pode levar à "morte do PNE".

Já no artigo Base Nacional Comum Curricular: um ponto de saturação e retrocesso, terceiro texto do Dossiê, Fernando Luiz Cássio apresenta reflexões e argumentos mostrando que a BNCC, política central da reforma educacional pretendida pelo Governo Golpista, torna-se ponto de saturação de um projeto de centralização curricular iniciado há mais de 20 anos, com os Parâmetros Curriculares Nacionais. Além disso, o autor explora elementos recentes da implantação da Base, a partir das agendas da Fundação Lemann, sublinhando que a complexidade desses processos dificulta ações de resistência organizada à BNCC.

Os três textos seguintes trazem reflexões sobre projetos em disputa, na sociedade brasileira, que colocam em risco a garantia do direito à educação e o princípio da gestão democrática, com a militarização das escolas públicas e o Projeto "Escola Sem Partido", além da reflexão de como o Golpe de 2016 se constitui como uma derrocada do direito à educação. No primeiro deles, Catarina de Almeida Santos e Rodrigo da Silva Pereira debatem, no texto Militarização e Escola sem Partido: duas faces de um mesmo projeto, o processo de militarização das escolas públicas brasileiras e o movimento/projeto "escola 
sem partido", apontando que esses processos fazem parte de um projeto hegemônico e conservador e colocam em risco direitos fundamentais e preceitos constitucionais, dentre eles, os direitos sociais e, mais especificamente, o direito à educação e seus princípios, como definida e defendida na Constituição Federal de 1988 e na atual Lei de Diretrizes e Bases da Educação Nacional.

O segundo texto a abordar a temática, escrito pelas autoras Miriam Fábia Alves, Mirza Seabra Toschi e Neusa Sousa Rêgo Ferreira, é A expansão dos colégios militares e a diferenciação na rede estadual. Nele, as autoras se propuseram a entender como o Governo de Goiás transformou uma ação isolada em política pública de diferenciação desta rede estadual, analisando a militarização das suas escolas, tomando como ponto de partida o movimento histórico que possibilitou a entrega das escolas estaduais para a Polícia Militar e seu processo de expansão.

No terceiro destes três textos, $O$ desmantelamento do direito a educação no pós golpe, João Paulo de Souza da Silva e Danielle Scheffelmeier Mei discorrem sobre os efeito do golpe de 2016 na negação do direito à educação, analisando o período de 2013 a 2017. Os autores buscam relacionar as políticas de austeridade com a redução de investimentos na educação e com as mudanças na legislação que aconteceram de maneira muito acelerada e sem o debate público coerente e consciente.

O texto que finaliza o Dossiê aborda uma temática central para a garantia do direito à educação, qual seja, a formação de professores. Assim, em Políticas de formação de professores: construindo resistências, Katia Augusta Curado analisa as políticas do campo da formação, propostas no atual Governo Federal (2016-2018), com foco no programa de Residência Pedagógica. A autora afirma que o programa é orientado por uma política de pragmatismo na concepção de formação de professores; e indica elementos de resistência para uma política de formação e profissionalização, com base na epistemologia da práxis, nos termos defendidos pela Associação Nacional pela Formação dos Profissionais da Educação (Anfope).

Ao contrário do que seria de se esperar, as perspectivas do futuro imediato da educação brasileira apontam para um recrudescimento de todas as políticas de (des) democratização e para a necessidade de, heroicamente, prosseguirmos em nossa luta para a superação da supremacia neoliberal dos contratos impostos pelo mercado em detrimento das garantias da nossa Constituição Cidadã. 


\section{Notas}

1 Reino Unido, Canadá, Austrália, França e Suécia e Brasil são os países que possuem um sistema de saúde público universal.

2 A Constituição Federal de 1988 estabelece subvinculação de recursos para a saúde, mas o montante investido nem sempre é suficiente para atender com qualidade toda a população. Como um direito social fundamental, é preciso lutar para que os nossos governos invistam mais em saúde, aperfeiçoem o Sistema e garantam o direito previsto.

\section{Referências}

BRASIL. Constituição (1988). Constituição da República Federativa do Brasil. Brasília, DF: Senado Federal, 1988.

Emenda Constitucional no 95, de 15 de dezembro de 2026. Disponível em: <http://www. planalto.gov.br/ccivil_03/Constituicao/Emendas/Emc/emc95.htm>. Acesso em: out. 2018.

DWECK, Esther; OLIVEIRA, Ana Luíza Matos de; ROSSI, Pedro. (Coord). Austeridade e Retrocesso: Impactos Sociais da Política Fiscal no Brasil. São Paulo: Brasil Debate e Fundação Friedrich Ebert, 2018.

TODOROV, Tzvetan. Os inimigos íntimos da Democracia. Lisboa, Edições 70, 2017. 